\title{
Interview
}

\section{In conversation with Ivor Browne}

\author{
David Healy interviewed Professor Browne recently at the Academic Unit, North Wales \\ Hospital
}

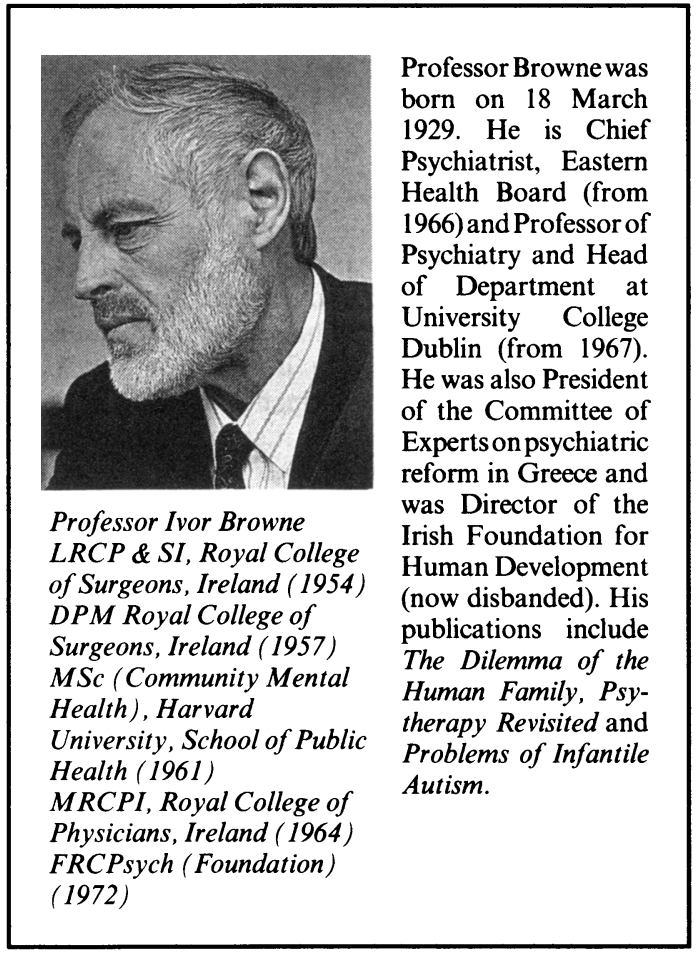

How has Irish psychiatry changed over the last 30 years?

I had worked in St John of God's during 1957 and 1958 so I had some idea of what Irish psychiatry was like but the real beginning for me was when I went to visit Grangegorman, towards the end of my time in St John of God's.

I went there in the evening when all the patients had returned to the wards from their various occupations so it was perhaps the worst time to go, but I did not know that. There were over 2,000 patients in St Brendan's then, with no segregation by age or diagnosis, only that the hospital was divided into male and female sections and never the twain should meet. Otherwise, all kinds of people were locked in together. I can still see as clear as day, while walking through the female admissions block, a young demented epileptic like a gnome, banging a screen and screaming, beside a gentle old lady who could have been my mother or yours, who had been admitted that day and was clearly quite sane, just sitting up in bed and literally shivering with terror. It was terrible.

Then I went down to the female disturbed ward which was in the old building - the original Richmond asylum. Inside there must have been more than a hundred people in a large room, jostling each other, some standing on their heads, and in the middle I could see a nurse bobbing up and down like a cork on a rough sea. It was literally like Bedlam. After that I went into the old dining room which was a temporary building like a huge aircraft hangar. There people were throwing plates. Nobody was allowed to use knives or forks. It was as bad as anything I was later to see in Leros.

When I returned to Ireland in 1962 to work in St Brendan's I got some insight as to why it was like this. Every day new people were admitted so they had to clear the previous admissions to make vacancies. This meant that the previous lot were transferred to more chronic wards. So people who nowadays would not come into hospital at all or would simply be admitted for a few days or a week, would have to be transferred to a more chronic ward before there was time for the acute disturbance to settle down. Then they would simply get lost, remaining in the hospital indefinitely; indeed some of them are still there as elderly patients.

Throughout his career John Dunne saw every patient who was discharged. No-one could get out without going through his Discharge Board. That was one of the most frightening things. You could find someone that you thought there was hope for, and you could work with them for several weeks to get them to the Board, ready for discharge. Although they might now be fully well he would look through the casenotes and if he found, for example, that they 
had attempted suicide ten years earlier he would say, "I think you had better stay in another while". The patient would literally lose hope and collapse back into illness in front of your eyes.

Originally he also personally admitted all the patients. But there was a famous case that brought this to an end. He was at the Gaiety Theatre one night when a patient came in - a rather litigious alcoholic, a lawyer I think. And he was admitted without John Dunne seeing him. The fellow took legal action because the medical superintendent hadn't seen him so they passed a Bill the next day through the Dail (Irish Parliament) making it possible for him to delegate function of admission. It was done within 24 hours.

Subsequently, I went to St Loman's, one of the ex-TB hospitals which had been taken over for psychiatry and was under the direction of Dr Vincent Crotty, one of the early pioneers of community psychiatry in Ireland. At that time it was allowed to take only female patients transferred from St Brendan's. Initially it was not allowed to admit directly or to discharge. Later, during my time there, we were allowed to discharge patients directly but all admissions came as transfers from St Brendan's to ease the overcrowding in the parent hospital.

The same was true of the other big mental hospital on the north side of Dublin - St Ita's, which also had over two thousand patients, all of them transfers from Grangegorman. During the short period I worked in St Brendan's everyone was on the move. All of the staff, nurses and doctors, were-like the patients - being transferred regularly from ward to ward. As a doctor I was always doing a locum for someone else so one seldom saw the same patients or nursing staff twice, unless one made a tremendous effort personally to follow some patient for whom one thought there was hope, as they were transferred from one ward to another. It was quite a terrifying set-up. It also represented, although I did not realise it at the time, a major deterioration from what the hospital had been like in earlier days.

It's interesting. Originally Dean Swift opened St Patrick's which was the first mental hospital in Ireland but it was private. The first public mental hospital was Grangegorman. On the same site there was the old north Dublin workhouse and this had built up an increasing population of "pauper lunatics". To deal with this problem the first purpose-built mental hospital was erected, under the auspices of the Duke of Richmond in 1812-hence it was first known as the Richmond Asylum. In the early days it took patients from all over Ireland but as numbers increased and as mental hospitals were built around the country, it came to concentrate on Dublin and the surrounding Eastern counties.

The early superintendents of the hospital were lay people but it began to come into its own in the $1850 \mathrm{~s}$ under the Wrigleys. Mr and Mrs Wrigley were lay people. He was the superintendent and she was the matron. Until quite recently you could hear some of the older people around Dublin refer to the hospital as the Wrigleys.

The main point I want to make about those early days is that in Wrigley's time and that of the next superintendent, Joseph Lalor, the first medical superintendent, the whole hospital was geared to what we would nowadays call industrial therapy mainly trades and shops for running what was in effect a small town. All the patients were employed and there was almost no restraint used.

In Dr Lalor's time it was even more interesting. $\mathrm{He}$ brought in the full national school curriculum. He had virtually the whole adult population involved in education. There were no suicides and he had completely done away with restraint. So when I saw it in 1958 there had been an enormous regression.

It would take a better psychiatric historian than me to answer the question but I have often wondered about the regression in asylum conditions that took place in Grangegorman and elsewhere in the UK and the United States as these hospitals were taken over by medical superintendents. It may be a coincidence that this deterioration happened when psychiatry began to be medicalised but it seems to me that this brought about an attitude of "Well, we needn't bother with all that stuff, social and moral work, we'll have the medical answer soon".

This, of course, created problems because it was the very success of the moral movement that created the mental hospitals which then grew and grew. With medicalisation, even though their discharges in the early years were as good as they are at present, the populations began to grow, and to grow more rapidly with increasing medicalisation. You can see it after Lalor's time in the case of Grangegorman. The population kept growing and had to be regularly decanted. First they opened Ardee Hospital for County Louth, then they built St Ita's in north County Dublin; when the population there increased to over 2,000 they transferred hundreds of patients to ex-TB hospitals like St Loman's and St Mary's. This is the same process that could be seen elsewhere in the Western world and the situation kept on deteriorating until it reached the indescribable conditions I saw when I visited it in 1958.

\section{John Dunne was your predecessor?}

Yes, he would have come in around 1936 and went right up to 1966 when I took over.

\section{So in effect 1930s thinking was dominate through to} the '60s?

Yes it did, in fact, but John Dunne was considered quite a pioneer. He introduced malaria treatment 
for syphilis and other innovations such as ECT and insulin coma therapy.

\section{Was there syphilis in Ireland?}

Yes, in over a third of the patients. Some of the old nurses would tell you terrifying stories of people in an advanced state of decomposition whose bodies were held together by sheets. GPI was a major diagnosis around the turn of the century.

\section{Even in Ireland?}

Yes, very much so.

That is interesting because the debates in the Journal of Mental Science around 1900 on the issue of why the Irish had more lunatics than the English agreed that it could not be because of syphilis-because the Irish didn't have it.

In fact I think it was a very similar picture. I do not know the exact figure but I know from talking to older nurses that it was a major factor just like elsewhere.

Is this a bit like the Irish and suicide-we just don't have it?

Yes, I would say the main factor for our being said to have more psychiatric illness than other Western countries was primarily that we had more mental hospital beds per head of the population. You had this extraordinary building energy in the 19th century. Nearly all the mental hospitals were built in the period 1830 to 1880 . Hospitals were built for a population of more than eight million people and as well as that all the workhouses and county homes were built. So there was an enormous warehousing operation going on. Then, following the great famine, between 1850 and the turn of the century the population more than halved. And, of course, if you had mental hospital beds they would be filled, particularly in a situation of poverty. By the early years of this century in a poor county such as Leitrim one person in a hundred of the population was actually in a mental hospital.

So I think that this is the major factor for the discrepancy in terms of hospitalised mental patients between here and the UK. I think Dermot Walsh in his three county study now seems to indicate that there is not actually more schizophrenia in Ireland. There are simply more mental hospital beds for people to hide in or retreat to. I think very often it was the case of "going in" for the hard winter months. Of course, once you were in then you developed the symptoms. The sociologic reality was that people were simply unable to manage the misery of life outside and it was easier to retreat into a mental hospital.
To return to the history of Grangegorman, around 1860 you had a large hospital with up to 1,000 beds, with no mechanical restraint, very little suicide, very little disturbance and almost the entire patient population involved in the full school curriculum of that period. By the turn of the century you had this appalling mess with patients doing nothing and large wards with tremendous disturbance. And this was how it was pretty much still when I came into the job of Chief Psychiatrist after John Dunne in 1966.

\section{Did both posts of Chief Psychiatrist for the Eastern Health Board and the Chair in University College Dublin go hand in hand?}

No, by getting the Chair a year later I created that relationship. There were no joint posts at the time. But having seen this happen, the authorities subsequently set up the other Professorial chairs which came later as joint appointments - Peter Beckett and then Marcus Webb in Trinity, Tom Fahy in Galway and Bob Daly in Cork. Their joint appointments were chairs and Clinical Directorships but the job I got was really the old Medical Superintendent job which they put a gloss on by calling it Chief Psychiatrist. There was a notion that there would be external facilities developing which did give me some latitude. But it was the following year that the chair actually came up. It was the only psychiatric chair in the country at that time. I don't think there was even one in Belfast.

Maybe we should talk about its history because I think it was pivotal in the whole development. In John Dunne's time the Chair of Psychiatry in UCD (University College Dublin) was traditionally associated with the public mental hospital but psychiatry was of no importance and the students simply came to the hospital to do a few clinics. His retirement ushered in a new era. The importance of the chair when I started was what it meant for the changing status of public psychiatry. As was the case in most places pre-NHS in Britain, anyone who could scrape any money together would go to the private mental hospital. When they ran out of money they drifted all the way down to the public facility. So you had a ghetto service of people who were chronic by the time they came into it or else poor. It was clear to me that unless we could in some way change it the public service was always going to remain the ghetto service, lagging behind. At this time there was a huge battle within UCD regarding the position of the university in relation to the general teaching hospitals and private psychiatric hospitals. The authorities of the university at that time wanted to strengthen the role of the college vis-a-vis the general teaching hospitals. The two teaching hospitals were really like feudal empires over which the university had little control even as regard the Chairs in Medicine and Surgery. 
In this set-up, psychiatry was pivotally placed because up until then the psychiatric chair was of no importance and was not attached to either general teaching hospital. John Dunne used to do six or seven clinical demonstrations for the students on the way through and that was that.

So Professor Tom Murphy, who later became President of the college, put his weight behind the psychiatric chair. He was registrar of the university at that time. St Vincent's were aware of the situation but they didn't have a psychiatrist directly attached to the hospital. It was assumed by everyone that as soon as John Dunne retired Dr Des McGrath, who had returned from Magill in Canada some years earlier, would automatically get the chair. But because he hadn't a direct attachment to St Vincent's they did not quite get behind him. The other main teaching hospital, the Mater, did not wake up to what was going on until too late.

At that time getting a Chair in UCD was an appalling procedure. They did not have a Board of Assessment or a proper interviewing situation as now exists. You had to visit every academic in the national university to look for votes. Several hundred people. I had to go to Galway, Cork. It was appalling. I would have given up on it if was just a personal thing. But it was the obvious key importance of it that kept me at it.

It was very interesting. It was the biggest battle for a chair in the history of the university so Tom Murphy tells me, although each chair was a bit of a battle at the time. I think Des McGrath would normally have won easily. I was very young and just back from Harvard so there was little hope. But late in the day the Mater realised what was happening and they put Professor Sean Malone forward. The political party, Fianna Fail, ended up becoming so involved that they actually put the whip on the governing body and the senate to ensure that all those with Fianna Fail affiliations would vote for Malone. It was as extreme as that.

This divided the vote between the two main teaching general hospitals and it was this that let me slip through the middle. I think this was the turning point for the development of psychiatry in Ireland because now you had a major professorial chair, the only psychiatric chair at that stage, centred in the public service.

With the combined posts of Chief Psychiatrist and the Professorship I was able to go in and negotiate not only with St Patrick's and St John of God's and get them to take on public sectors but also with the Mater and St Vincent's and get them to set up proper psychiatric units in the general hospitals.

I also recruited Noel Walshe back from Canada. Sean Malone in the meantime was proposed by the Mater. So where we had just one chair, mainly through my efforts they created two satellite clinical chairs. That may have been a mistake but UCD wanted to get back to the old pattern. And of course from then on, particularly when Tom Murphy retired, they regretted my being there and would have liked to get rid of me and revert to the usual pattern of a professorship in each of the two main teaching general hospitals.

The major thing that came out of this was something more like the National Health System in Britain, in that you had a unified psychiatric system even though there were private elements in it. The other thing was the notion of joint academic chairs with public appointments which hasn't really worked out very well. The same difficulty I had, to have time to look after the academic end properly, the general hospital and some aspect of the community psychiatric service, means you tend not to do anything properly. This was my main disadvantage all along, not being able to give the proper attention and perhaps relatively neglecting the academic side and research side because my main interest coming into the post was in the public service and the development of a community psychiatric system.

Having the Chief Psychiatrist job along with the chair left me, of course, in psychiatric terms in a very powerful position. I began to negotiate initially with Norman Moore in St Patrick's because he was the key person. To his credit he did not say, "Go to Hell". He took seriously the notion of St Patrick's taking a catchment area. And that was the first big break in the divide between private and public. He was sensible enough to see that sooner or later the public system was going to improve and that $\mathrm{St}$ Patrick's would have to have a public catchment area to ensure its future. So he was wise in that sense but he could easily have turned his nose up at it all. St John of God's tried to but once he came in then they had to follow suit. And that meant that you had a system which, while still very primitive, had five public catchment areas and two run by the private hospitals under contract to the Eastern Health Board, or the Dublin Health Authority as it was at that time.

How do you think that kind of structure relates to what is happening in the UK at the moment where there is this issue of possibly the NHS having to contract services from trust hospitals?

I assume it would be a similar kind of arrangement. In our case this has basically worked very well. Probably in terms of running an efficient service, the St Patrick's and St John of God's services work better than most of the Eastern Health Board public services. They do not use so many beds and because of their entrepreneurial tradition are more efficient. Nevertheless, this arrangement has ensured that the public sector is now the dominant psychiatric service, 
of which the private hospitals undertake a minor part.

In fact the Irish structure has influenced the British structure. I don't know if you know that, prior to setting up the Health Boards in 1970, which was the next big development, the consultant firmMcKinsey - were brought in to help plan the change and then used Ireland as a pilot when they were asked in turn to help the Department of Health in Britain plan its district psychiatric services. Since then District Boards have come in over in Britain.

\section{How do you mean they actually used Ireland?}

You see they did not have a managerial system in Britain even under the National Health, whereas Ireland pioneered the idea of a county manager with enormous power. They mainly got their power to try and combat nepotism. Part of the idea was to set up a local appointment system aimed at stopping local councillors having their friends in jobs. So they gave the power instead to the County Managers and at that time, prior to setting up the Health Boards, health services were part of the County Council administration.

Britain in effect took that managerial idea from Ireland with its good and bad points. Since then you have had the problem with managers who have greater and greater power and with regional Health Boards, but I think the Eastern Health Board would have predated the regional boards in Britain and the appointment of lay managers taking more and more power on to themselves. So McKinsey came over and they told me at the time that they were consulting with the NHS and the Department of Health in Britain. They told me quite clearly that they were going to use Ireland as a model for the reorganisation of health services in Britain.

\section{Training in Ireland is in a bit of a mess though isn't it?}

I think that it comes back to the colonial tradition in that the whole ethos in Ireland was not that you trained your own technical sector of the population to run the country but rather that you sent them elsewhere to see how it was done. Not only that but you produced for the empire. You either worked in the colonial civil service or you went to be a priest, a doctor, a lawyer. So we didn't develop any technical infrastructure or any real expertise in terms of helping the country itself. This is only developing since we joined the EEC so I think that's the main area for growth.

We have been very slow in organising higher training and in creating senior registrar posts. Whether we should have followed the British pattern on this or have gone down a different road, perhaps following the American pattern which might have made more sense, is a good question. But, given that we have remained part of the British College, I suppose there is no alternative to following the present line of development ... that is another thing I should add in-Dermot Walsh, myself and Des McCarthy thought a lot about a split from the British Royal College and the possibility of setting up a separate Irish College of Psychiatry.

\section{When was that?}

It is well over ten years ago; we attempted a coup d'état. It is dead now. We did not get sufficient support from the general body of psychiatrists. On the other hand, we could have combined with GPs or even with the College of Physicians. With medicine and surgery you have an Irish College. This could have given us more independence to make our own system of training.

So, despite the name "The Royal College of Physicians" and "The Royal College of Surgeons" in Ireland, you are saying that it is only actually in psychiatry that Irish members are actually part of a Royal College?

Yes. The medical and surgical colleges all have Irish degrees. We need not have lost anything. We could have kept the relation to the British College. It was really another example of Irish dependent colonial thinking - what we call "shoneenism".

\section{Shoneenism means what?}

As I understand it, it means kowtowing to the dominant colonial society. The man who wrote most clearly about this was Paulo Freire when he described the dominance of US power over the economically dependent South American societies specifically he was speaking in relation to Brazil and the whole attitude of feeling worthless in the face of another dominant culture - that in these situations people tend to collude with the dominant society. Now I think in Ireland we have tended to do that.

But why psychiatry in particular? I mean you would have thought psychiatrists might have understood these things better than surgeons for example?

In the 18th century Ireland had achieved a substantial amount of independence. The late 18 th century was a time of great development in Irish medicine. It was on a par with anywhere in the world. So it was at that time they set up the College of Physicians and College of Surgeons.

\section{But they were at the same time royal?}

They were royal but nevertheless they were preunion. In other words, there was an Irish parliament at the time. They saw themselves very much as an equal college like Edinburgh or London and they 
still retain that status. Whereas psychiatry only happened since then. It came about post-union. Therefore it stayed with what was the original organisation - the Medico-psychological Association and then when the Royal College was formed it went on to become an Irish division.

I suppose part of the reason they were against breaking away at the time we raised it was due to the question of the North of Ireland. If we had gone ahead with the move there was a risk the North would have separated from us if we had formed an Irish College.

\section{Tell me about your early training.}

My first job was in Oxford in the Warneford in 1956. That was very standard in terms of traditional psychiatry. I was not at that point tuned into any direction in psychiatry. But I should mention its impact on me. It was the first time I had left Ireland and although psychiatry was very traditional in the Warneford it had been a private hospital that dealt with the University. There was no Chair in Psychiatry in Oxford at that time. But the Warneford had traditionally been seen as the local mental hospital to deal with university people, so almost all the patients were either staff or students from Oxford.

This was significant for me because I had a typical Irish upbringing where you couldn't have a thought of your own. If there was some question someone told you the answer or you looked it up in a book. Here suddenly I encountered people, most of whom were patients, who when a question arose asked themselves what they thought about the issue because there was no one else who was going to think it out if they didn't. I remember that coming to me as an absolute revelation, like receiving a sudden blow on the head. I remember saying to myself - if they can think for themselves, why can't I do the same? That was the important lesson I learnt from that year's experience.

Then I came back to St John of God's and had a year and a half of fairly typical psychiatry. But looking back I think the thing I learnt there was scepticism of the claims for organic treatments. This was the high point of the phenothiazine era and other psychoactive drugs. And John of God's had these young middle-class patients coming up from the country manifesting acute schizophrenic breakdown. I saw this dramatic "cure", with all their symptoms dropping away, leading to discharge. By the end of a year and a half almost all were back again, only this time more chronic. If I had been there less than a year I would not have seen it. Whatever we were doing, it was clear to me we were not changing the process.

So these are the milestones that stand out - not the orthodox things that I was learning. Then thinking what to do, I saw an advertisement for a post in the Marlborough Day Hospital, under Joshua Bierer. It was situated in what had been Thomas Henry Huxley's private house. Bierer had used the mews and the garage at the back to turn into a night hospital. He had a day and night hospital by the time I got there but it was closed at the week-end.

\section{Who was Joshua Bierer?}

He was a pupil of Adler's who had come over as a refugee, I think, around the beginning of the War. He was really the pioneer who started community psychiatry in these islands, much more than Maxwell Jones, T. P. Rees, or anyone else. But he was a terrible writer and he made extravagant claims in almost illiterate English so nobody paid any attention. But he started the first real day hospital in the world - at least of the kind of thing we think about now - you know community mental health centres that have been developed since. Cameron started a day hospital in Canada around the same time but along more conventional lines. Joshua's was the first real community psychiatric day hospital to open in the Western world.

It did not work to a catchment area the way a day hospital now would but it worked at taking its own people in and preventing them from going on to hospital. In the year I was there I remember that we admitted only 20 on to mental hospital and every damn one of them was at the weekend. We used to be closed for the weekend. Afterwards he opened it at the weekend as well.

Even more remarkable in 1947 , just after the Second World War, he moved a whole lot of patients out of Runwell, I think it was, or whatever mental hospital he was working in then. Terrible characters who were totally psychotic. Moved them into a house with little or no supervision. That was years before anyone else thought of doing this, so really I would regard him as a true pioneer of community psychiatry but the world's worst publicist and his own worst enemy.

It was there also that I first had the experience of working with LSD. It was not Joshua Bierer who pioneered this but the other consultant - Dr Lingwho started using LSD. He became quite well known and wrote a number of papers on the use of LSD. Influenced by Ling's work, Bierer also was working with LSD and I was his registrar. Three nights a week we would have a group in which we would give LSD to patients who would stay overnight. I have to say I saw people manifest remarkable experiences and undergo radical change. At the time there was no clear understanding of the relation between some atypical psychotic states and early trauma, so retrospectively I don't think we understood very clearly at that time what we were doing, even though I 
saw a number of people who had been chronically disturbed for years totally transformed while I was there.

\section{He isn't a person who gets heard about now.}

No, because it is the writers who get heard about like Freud. Joshua's attempts at writing are terrible and he did write quite a lot of papers but they were almost gibberish and that is why I think, more than anything, that he was not noticed. But he was in the true line. Adler if you like was the first social psychiatrist. Joshua was analysed by him and he took on a lot of Adler's ideas, in particular the notion of psychotherapy being applied to a wide range of conditions including schizophrenia, just as much as depression or the neuroses. He had an amazing facility to break through to people - into someone who was mute. Once started he would be quite liable to keep them talking all afternoon. He could be psychopathic too-drifting off into something else, leaving them high and dry.

The only thing he is actually known for in the literature is as the person who invented the psychiatric social club. Really that is the least important thing he did. He had a number of these around Hampstead.

After that I then got a fellowship to the US - $\$ 300$ a month and travel. I wrote to various people and got offers from several places, including Yale. The most interesting reply I got was from Gerald Caplan who was in the Harvard School of Public Health so I decided that was the best. I divided my time there and did about eight months in the Mass General, where Erich Lindemann was Chairman. Then I moved on and did the MSc programme in mental health in the School of Public Health under Caplan.

So that pushed me further in the social direction. I spent that whole year looking at things like crisis theory, which Caplan had pioneered. I spent the summer on the West coast at a time when the joint commission was coming into being. Caplan was a significant adviser to President Kennedy's group so that the whole community mental health centre development in the States came largely out of the Boston experience. Lindemann had already opened the Wellesley Human Relations Centre which became the model for the mental health centre movement, which developed later. So you can see that my American experience moved me further towards community psychiatry.

You have had an unceasingly controversial career in Irish psychiatry but it is my impression that your current work on child abuse is perhaps polarising the brethren more than anything else you have done. Where did this interest of yours come from?

It came up first working with Bierer, using LSD. Describing this work later in the US, I found that the Americans with their analytic training invariably downplayed any suggestions I had that the issue of childhood trauma should be taken seriously, saying that what was involved was fantasy not reality. My problem was that reading Freud's early work and Pierre Janet at that time, I found that what I had been witnessing seemed to be much the same as they described and they had both also concluded that these traumas had really happened. I could never understand Freud's sudden change on this issue when, barely a year after presenting 'The Aetiology of Hysteria' paper in which he laid out unequivocally his seduction theory, he wrote the famous letter to Fleiss - "the awful realisation that most, not all, of these events were untrue..." For many years this remained a question with me and I could not understand this sudden change of heart, for he did not present any evidence as to why he changed, until the Masson book, Assault on Truth came out in the early '80s. In releasing the unpublished letters to Fleiss, Masson for the first time made clear the tremendous pressure and ostracism under which Freud was labouring during that crucial period around 1896.

When I came back to Ireland it was relatively easy to get LSD. One could get it from the company-I used to get it from Sandoz and I actually got formal approval from the Department of Health to use it. After coming back first, when I had more clinical time than later, I worked with a number of people and had some remarkable successes bring people through grief, early traumatic abuse, etc.

I particularly remember a woman who had lost her husband - he was electrocuted in Ballyfermot and she was presenting as totally psychotic. I had to go out to her house to get her a couple of times when the GP and her relatives had certified her. There would be ambulances and a crowd of people standing around, and myself and the community nurses would have to break into her house and give her an injection to bring her in. The last time this happened I said I am not having any more of this and I decided to give her LSD. My criterion at that time was that with anyone that nothing else touched I used to use LSD. We used to give LSD by mouth, about 50 micrograms, and raising it each session up to about 300 micrograms. About half an hour after they had taken it I would give them $30 \mathrm{mgs}$ of Methadrine IV to potentiate it.

I did all that with her several times but got nowhere except that she got more and more angry and started abusing me and threatening litigation. I remember this day having given her about 300 micrograms of LSD and she had become more and more abusive. I stood at the end of the bed and I just literally lost my temper and roared at her. She immdiately switched from being abusive and angry and contentious and litigious to roaring and crying. She imagined she was holding her husband's head in her hands and she was smelling the oil from his dungarees. It was literally as 
if you turned on a video of the scene of the death. She roared crying and went on crying until after several sessions she had fully worked through her grief. I saw her as an out-patient for a number of years but there were no further relapses and she remained totally well.

But at that time I wasn't thinking in terms of there being more than one traumatic event or a number of griefs. I only now and then came on histories of sexual abuse and then usually one or two more recent events. I did not realise the can of worms that was lurking below the surface. I normally stopped as soon as there was a bit of symptomatic improvement. I also at that time would try LSD with some chronic schizophrenic patients who were making no progress but I very quickly realised that all that happened was that they just became more psychotic. I very gradually began to see a separation between the people who have schizophrenia and those whom we might now term borderline or atypical psychoses.

I kept working with LSD through the 1960s. And we did quite a significant genetic study which was published in the American Journal of Genetics in the late '60s, looking at the effects of LSD on chromosomes, using patients on benzodiazepines as a control, because there was all this stuff about LSD damaging chromosomes at that time. Our study showed no difference or slightly more chromosomal breaks in people on benzodiazepines.

Finally, as a result of all the negative publicity from the use of LSD on the streets, I could not get it any more so I had to stop that work but I did continue up to the late '70s; I can't remember exactly what date. In the early ' 80 s I heard about Stan Grof's holotropic method. That brought me back into this kind of work. It was he who mentioned the use of Ketamine as well. So since then we have developed our present work and a much fuller therapeutic programme. Our understanding of what is involved in the capacity of people to block traumatic experience is much clearer and all that we have described under the theory of 'Unexperienced Experience'.

\section{Let us talk about training.}

I had felt for a long time that there should be a Chair of Psychiatry in Trinity. Norman Moran and I talked about this and he suggested approaching Peter Beckett who was working in Detroit with Gottlied, doing research into schizophrenia. One of the things I did when I went on the World Health Fellowship to the States in 1968 was to visit Peter Beckett in Detroit and try to recruit him back to Ireland. After my visit he said he was interested and we talked a lot about things. He agreed to come. Trinity were agreeable to coming up with the Chair but they wanted Norman Moore to take it. But he said, "No, there's no point. Get somebody young who could do something new".
That was how Peter Beckett came. Trinity were so upset that they then made Moore a Clinical Professor and that is why St Patrick's has a Professorship attached to the hospital as well as the main Chair which Marcus Webb now holds.

So Peter Beckett came back and here I would like to make a small, historical correction. It is commonly believed that Peter started the unified post-graduate psychiatric training scheme. In fact I had been working on that idea for some time and I remember specifically one day sitting for an hour with Peter in his car or mine, discussing would he consider coming in on the idea of joining up the Eastern Health Board with Trinity and UCD to set up a joint training scheme and he agreed.

Then we approached Moore and Tom Lynch, who was Professor at the College of Surgeons, and all four of us went down to the Department. By the time we arrived at the Department, Moore was talking about Peter Beckett's idea of unified training, which is fair enough. But just to put the record straight, because St Patrick's have tended to take the thing over since, it is actually historically incorrect. I remember working very hard on Peter for an hour or two to bring him around to my idea. That was how we started informally as a joint training scheme and I had to get it through UCD and he got it through Trinity.

Afterwards, with the development of the Royal College, training became more formally organised. But we already had our day release and so on and then the government created the statutory committee for postgraduate dental and medical education; the Irish psychiatric training committee became an official statutory sub-committee of this body. And then surgery and medicine and all the others came in on it. But we had already started it in psychiatry before anyone else, as an informal joint training scheme between the three medical schools.

Later it spread to Galway and Cork and became a national training scheme when Tom Fahy got his Chair in Galway and Bob Daly later in Cork. So that was how the scheme for the whole country came in and Cork and Galway joined it. Now it is a very formal thing with representatives from the Irish Division and from the universities and so on, but we had the basic idea working years before. It used to be organised from St Brendan's but then it gradually drifted over to St Patrick's, who proved more effective at organisation, particularly since Dr Frank O'Donoghoe became coordinator. So the whole thing now is seen as a St Patrick's development.

\section{Can we switch to your work in Leros?}

It's strange. Wolfgang Stabinov was the top civil servant in the social affairs division under the commissioner and Ed Fitzgibbon, who is Irish, was next in line under him. As part of Greece coming into the 
community in the early ' 80 s, rumours began to filter out that this island existed with pretty awful psychiatric conditions. Some time in the very early ' 80 s there was an article in Stern magazine in Germany, showing pictures of naked patients. So these two civil servants - Stabinov, who had a mentally handicapped son, and Ed Fitzgibbon - took this very personally. They went way beyond their ordinary civil service brief and creatively put it to the commission that it would not be appropriate for Greece to enter unless something were done about the state of psychiatry there. Because it wasn't just Leros. There were terrible conditions all over the country. As a first step they got agreement from the Commission and then they set up a group of experts. I don't know how Ed Fitzgibbon heard about me because if he had asked the Department of Health I would have been the last one they would have recommended. In fact, they tried to block my being selected but he insisted and, with the backing of the Social Affairs Commissioner, he was in a very authoritative position. So that forced their hand but the Department were never happy about it.

They had Alan Maynard, the health economist from York University, he was a great chap, myself from Ireland, nobody from France, originally one Italian but two eventually from ENAIP, because there was great enthusiasm for the whole Italian community psychiatric movement at the time. There were also two Greeks and a German psychologist. That was the team of experts and they made me Chairman - or, as it is termed in Brussels, President of the group. Our job was to visit Greece, so we went over.

It was interesting because Planning for the Future took nearly five years to write. We wrote our report which is not too different-indeed perhaps more comprehensive - in about four months and we had to travel from the very north of Greece right down to Crete. We went in sub-groups and divided up the committee and wrote the report on the situation of psychiatry in the whole of Greece. Now the thing about all this was that the commission then voted something like 60 or 80 million ecus specifically for psychiatric intervention. This is actually unique in their terms because they are supposed to support only training programmes towards open employment but they put it through on the basis that in order to get to the point of vocational training they would have to do something with the infrastructure.
The report came out in April 1984. We had started sometime in the Autumn of 1983.

\section{Why was it the rest of us only began to hear about it in 1988 or whenever?}

We had to keep quiet because there was a very delicate situation vis-a-vis the EEC. They could not do anything directly. We produced our report. They gave it to the Greeks. The Greeks then came back with their answer which was effectively the same report - in order to get the money. Then they started to implement a scheme creating general hospital units, mental health centres, hostels and so on all over Greece.

The thing that had spear-headed the whole thing was Leros but it was the one place that they couldn't get themselves together, even to use the money that was being offered. They still haven't. There were bits of activity but we could not publicise what was wrong. Two or three years later, about 1986 or 1987 , we actually had an international seminar down there to try and focus public attention. And that hit the newspapers a bit. But even that didn't do it. It was only when The Observer article came out that it really hit the headlines in this part of the world but even then we were not able to do anything because the EEC could not directly criticise the Greeks. They could only offer help and lay down conditions under which they would provide finance but they could not force them to do anything.

A couple of years ago the Dutch sent in some volunteers and with the aid of a very fine psychologist from Thessaloniki in Northern Greece they set to work in the worst unit where most of the patients were naked in their own filth. They completely transformed one section of this unit, had 20 patients living like civilised human beings and were just preparing to generalise the programme to other sections of the hospital when the government changed. Since then, as far as I know, all of this activity has ceased and everything is drifting back once again to where it was.

The one thing we did achieve to some extent was to stop the admissions into Leros. Originally there were 3,000 there, then it went down to 1,800 . There were about 1,800 when we first went there and it is now down to 900 . The trouble is that this drop has not happened because anyone has been moved out of the place but is apparently due to the death rate which seems to be appalling - but that's another story. 